\title{
Interannual Variability in the Decay of Lower Stratospheric Arctic Vortices
}

\author{
Darryn W. WAUGH and Ping-Ping RONG \\ Department of Earth and Planetary Science, Johns Hopkins University, USA
}

(Manuscript received 21 May 2001, in revised form 15 February 2002)

\begin{abstract}
The interannual variability of the decay of lower stratospheric Arctic vortices is examined using NCEP/NCAR re-analyses between 1958 and 2000. There is large interannual variability in the characteristics of the decay of the vortex air, with very different characteristics for early and late vortex breakups. In early breakup years (when the vortex breaks up in February and early March) the remnants of the vortex survive as coherent potential vorticity structures for around two months, whereas in late breakups (late April and May) the potential vorticity remnants quickly disappear. There is a similar contrast in the stirring around the vortex between early and late breakup years, as diagnosed by the lengthening of material contours in contour advection calculations. In years with an early breakup there is a gradual decrease in the stretching rates from large winter to small summer values, whereas in late breakup years stretching rates are roughly constant until late spring when there is a rapid decrease. These differences in the decay of coherent vortex structures and stirring suggest that there are large differences in the mixing of vortex air into the surrounding middle latitudes between years with early and late breakups.
\end{abstract}

\section{Introduction}

In recent years there has been considerable interest in the timing of the breakup of the wintertime polar vortex in the polar lower stratosphere (e.g., Zurek et al. 1996; Waugh and Randel 1999; Pawson and Naujokat 1999; Waugh et al. 1999; Zhou et al. 1999). These studies have shown that there are large interannual variations in the timing of the breakup of the Arctic vortex, with an increased tendency for more persistent vortices (late breakups) during the 1990s. These variations in the persistence of the vortex have a significant impact on interannual variations in polar ozone: There

Corresponding author: Darryn W. Waugh, Department of Earth and Planetary Science, 320 Olin Hall, 3400 North Charles Streets, Johns Hopkins University, Baltimore, MD 21218, USA.

E-mail: Waugh@jhu.edu

(C) 2002, Meteorological Society of Japan is generally reduced ozone during years with a late breakup because of both reduced transport of ozone-rich air into the polar lower stratosphere and increased chemical destruction (as a result of the lower polar temperatures). A continued delay in the breakup of the Arctic vortex may then result in a delayed recovery of the ozone layer as the stratospheric chlorine loading decreases (Shindell et al. 1998).

The timing of the vortex breakup is, however, not the only important issue with regard to the winter to summer transition. The characteristics of the vortex breakup, in particular the mixing with surrounding air, are important for understanding the residual effects of chemical processing inside the polar vortices. For example, several recent studies have examined the impact on midlatitude ozone depletion of the mixing of ozone-depleted vortex air into midlatitudes following the vortex breakup (e.g., Knudson et al. 1998; Knudson and Gross 
2000). Although many studies have examined the interannual variability in the timing of the breakup of the Arctic vortex, relatively little attention has been paid to the mixing processes during the breakup. The exceptions are a few studies that have examined the breakup during individual years, when observations of trace gases are available.

The pioneering, and still only detailed, studies of the breakup of stratospheric vortices are those of Hess $(1990,1991)$. In these studies, Hess examined the final warming (breakup) of the middle stratosphere Arctic vortex in both a general circulation model and the Limb Infrared Monitor of the Stratosphere (LIMS) observations of the 1978/79 vortex. The observations show a lengthy transition to the summer circulation regime in 1979, with long lasting coherent vortices. In contrast, in the model there was a rapid transition into the summer regime (which occurred around 2 months later than in 1978/79; May compared to March). However, even though the simulated transition was rapid, Hess' analysis indicated that features in tracer fields were "frozen in" the summertime easterly flow and that there was also slow mixing of vortex remnants within the model.

In more recent years, in-situ observations of trace gases have been made following the vortex breakup and have been used to estimate the mixing of vortex air into middle latitudes. In particular, Waugh et al. (1997) used aircraft observations made in April-May 1993 together with contour advection (CA) calculations and a simple one-dimensional advection-diffusion model to examine the mixing during the breakup of the 1992/93 lower stratospheric vortex, and estimated that filaments of vortex air were completely mixed into the surrounding mid-latitude air within around 30 days (similar estimates were obtained by Balluch and Haynes (1998)). However, a more recent analysis suggests that this may be an underestimate of the mixing time (Plumb et al. 2000). More recently, several tracer observations in late June 1997 show remnants of vortex air over a month and a half after the vortex broke up (e.g., Hermann et al. 1998; Strunk et al. 2000), implying slow mixing of vortex air with surrounding air (i.e., mixing time of longer than a month and a half). Given that estimates of the mixing are available for only a couple of years and that the inferred mixing times are very different (and very uncertain), there remain large uncertainties in the mixing during the vortex breakup. In particular, it is not known whether there is large interannual variability, and whether, as suggested by the results of Hess (1991), the mixing varies with timing of the vortex breakup.

We examine here the interannual variability in the characteristics of the Arctic lower stratospheric vortex using meteorological re-analyses covering the period 1958 to 2000. Two aspects of the vortex breakup are examined. Potential vorticity (PV) analyses are used to examine the breakup and decay of coherent vortex structures, while contour advection calculations driven by the analyzed winds are used to examine the stirring during/following the breakup.

\section{Data and analysis}

Meteorological data from the National Centers for Environmental Prediction (NCEP)/ National Center for Atmospheric Research (NCAR) reanalyses (Kalnay et al. 1996) are used to examine the vortex evolution and transport in the lower stratosphere over the period 1958 to 2000 . As discussed in the Introduction there is large interannual variability in the timing of the breakup of the Arctic vortex. This can be seen in Figure 1 which shows the date of the vortex breakup at $500 \mathrm{~K}$ (around $21 \mathrm{~km}$ ) between 1958 and 2000 using the criteria of Nash et al. (1996). The Nash et al. (1996) criterion defines the vortex edge as the location of maximum PV gradients (in equivalent latitude space based on the PV distribution) constrained by the location of maximum wind speed calculated around the PV isolines, and the breakup date is defined as the date when the average wind speed along the vortex edge falls below a critical value $(15.2 \mathrm{~m} / \mathrm{s})$. The average breakup date of the 1958 to 2000 period (dashed line) is April 11, but the breakup has occurred as early as Feburary 5 (in 1958) and as late as May 8 (in 1997). (The precise date of breakup is sensitive to the criteria used to define the breakup, but different criteria show similar variability to that shown in Fig. 1, see Waugh et al. (1999).)

Given the large variability in the timing of the vortex breakup we focus here on differences between early and late breakup years. We focus 


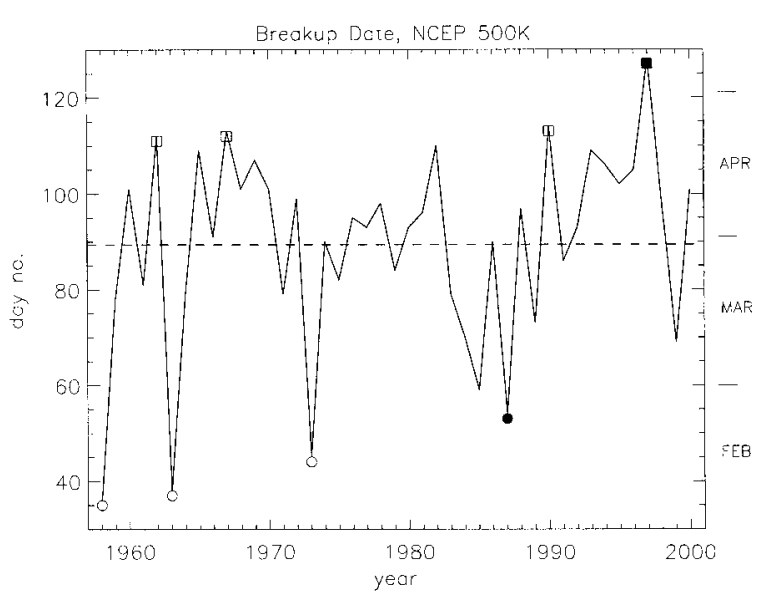

Fig. 1. Variation of the breakup date of Arctic vortex at $500 \mathrm{~K}$ from 1958 to 2000 determined using the Nash et al. (1996) criteria. Filled symbols mark the two years (1987 and 1997) which are examined in detail, and unfilled symbols other early/late breakups examined. The dashed line shows the average date of the breakup.

initially on the breakups in 1987 (filled circle in Fig. 1) and 1997 (filled square), which are the earliest and latest breakups, respectively, in the satellite era (1979 to present). ${ }^{1}$ We then examine the characteristics for several other early and late breakups (unfilled symbols in Fig. 1).

Analyzed PV fields are used to characterize the structure and evolution of the vortices. Maps of PV on isentropic surfaces are used to examine how the vortex breaks up and also the existence, and evolution of, coherent vortex remnants formed during the breakup of the main vortex. The temporal variations in the size of the vortices is quantified using the area enclosed by PV contours, expressed as the "equivalent latitude" $\varphi_{E}$ of a zonally symmetric PV distribution.

1 The Arctic vortex broke up very early in the most recent winter, 19 February 2001, and this is now the earliest breakup (according to the Nash et al. (1996) criteria) in the satellite era. However, most of the analysis presented here was performed before this breakup occurred.
The PV provides information on the evolution of the vortex but, because of the limited resolution of the reanalyses $\left(2.5^{\circ}\right.$ longitude by $2.5^{\circ}$ latitude) and non-conservative (radiative) effects, it cannot be used to examine the details of the stirring and mixing of conserved tracers. To examine the stirring we perform highresolution transport calculations driven by the reanalyzed winds.

Contour advection (CA) calculations (Waugh and Plumb 1994; Norton 1994) are performed to examine the generation of filamentary structures and cascade from large to small scales. Previous studies indicate that CA calculations driven by analyzed winds can reproduce observed fine-scale tracer features (e.g., Waugh et al. 1994; Plumb et al. 1994; Appenzeller et al. 1996, Newman et al. 1996). The strength of the stirring is quantified by calculating the growth rate of the contour length (e.g., Pierce and Fairlie 1993; Chen 1994; Waugh et al. 1994, 1997). The length of contours in CA calculations increase approximately exponentially with time, e.g., length $l(t) \approx l(0) \exp (S t)$, and the contour-lengthening exponent $S$ is a measure of the stretching characteristics of the flow. Although $S$ is often related to Lyapunov exponents this is not strictly the case, see Ngan and Shepherd (1999).

\section{Potential vorticity}

Visual inspection of maps of PV shows large differences between early and later breakup years, not only in the timing of the breakup but also in the rate of decay of the vortex. These differences can be seen by comparing Figs. 2 and 3 which show PV maps on the $500 \mathrm{~K}$ surface for 1987 and 1997, respectively. In 1987 the vortex broke apart in late January, and although the size of vortex remnants decreased the remnants survived for over 2 months and did not disappear until early April (Fig. 2). In contrast, in 1997 there is still a strong vortex on May 1, but this vortex rapidly disappeared and there were no remnants left within a month (Fig. 3). The differences in the decay of the vortex in these two winters can also been seen in the temporal evolution of the equivalent latitude (area) of PV contours, see Fig. 4. The vortex in early January 1987 is stronger than in 1997 (i.e., larger area and meridional gradients), but whereas the vortex area gradually 

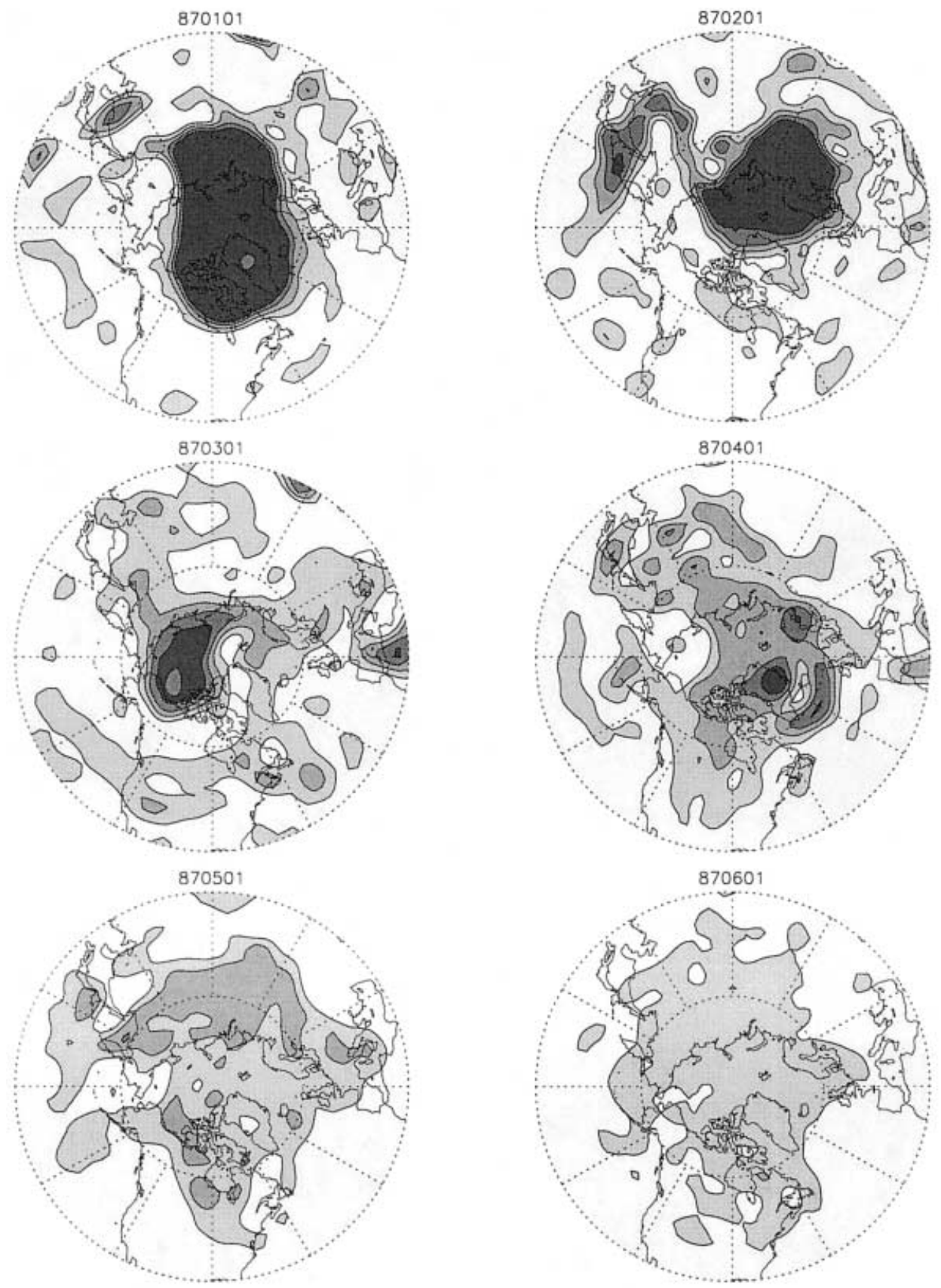

Fig. 2. Maps of potential vorticity PV (contours) on the $500 \mathrm{~K}$ isentropic surface for first of each month between January and June for 1987 . Contours plotted correspond to $\mathrm{PV}=(30,35,40,45)$ PVU (1 PVU $\left.=1 \times 10^{-6} \mathrm{Ks}^{2} \mathrm{~kg}^{-1}\right)$.

decreased from February to April in 1987 the vortex area remained roughly constant until early May in 1997, at which point the vortex disappeared quickly.

The PV analyses for other early and later breakup years shows the same contrast as the above years. Figure 5 shows maps of PV one month after the breakup for 3 other early breakups (left hand side) and 3 other late breakups (right hand side). Coherent vortex structures with high PV can still be seen for the early breakups, whereas the PV field is flat for 

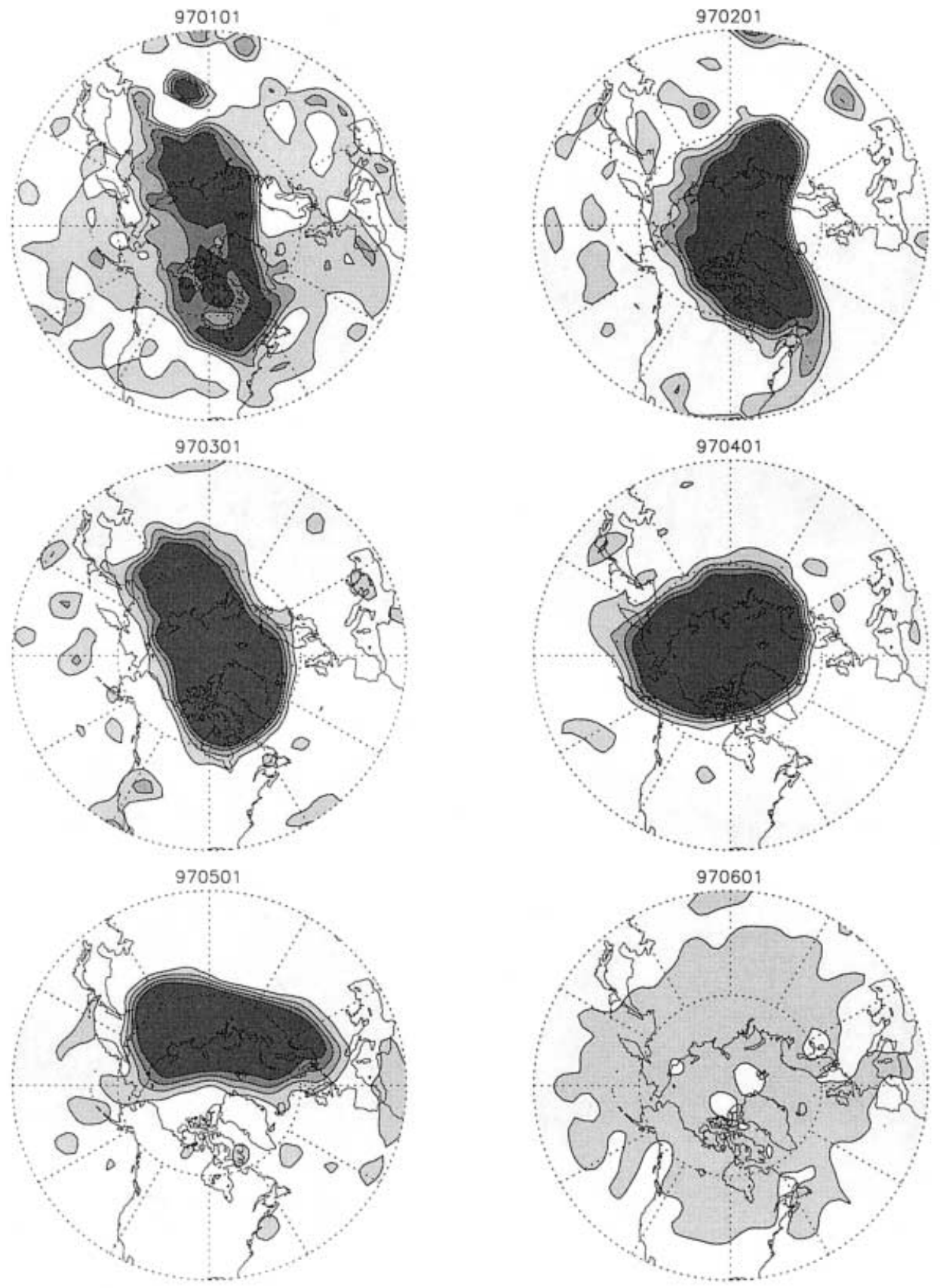

Fig. 3. As in Fig. 2 except for 1997.

the late breakups. The contrast between early and late breakups is also clearly seen in the temporal evolution of the equivalent latitude of PV contours. Figure 6 shows the equivalent latitude of the $\mathrm{PV}=42 \mathrm{PVU}$ ( $1 \mathrm{PVU}=$ $1 \times 10^{-6} \mathrm{Ks}^{2} \mathrm{~kg}^{-1}$ ) contour which is representative of the vortex edge (see bold contours in Fig.
4) for (a) early and (b) late breakup years. In all early breakups there is a gradual decay in the area enclosed by the PV contour, whereas in the late breakup years the area is fairly constant until the vortex breakup when there is a rapid decay. This contrast also holds for other early and late breakups not shown. An inter- 

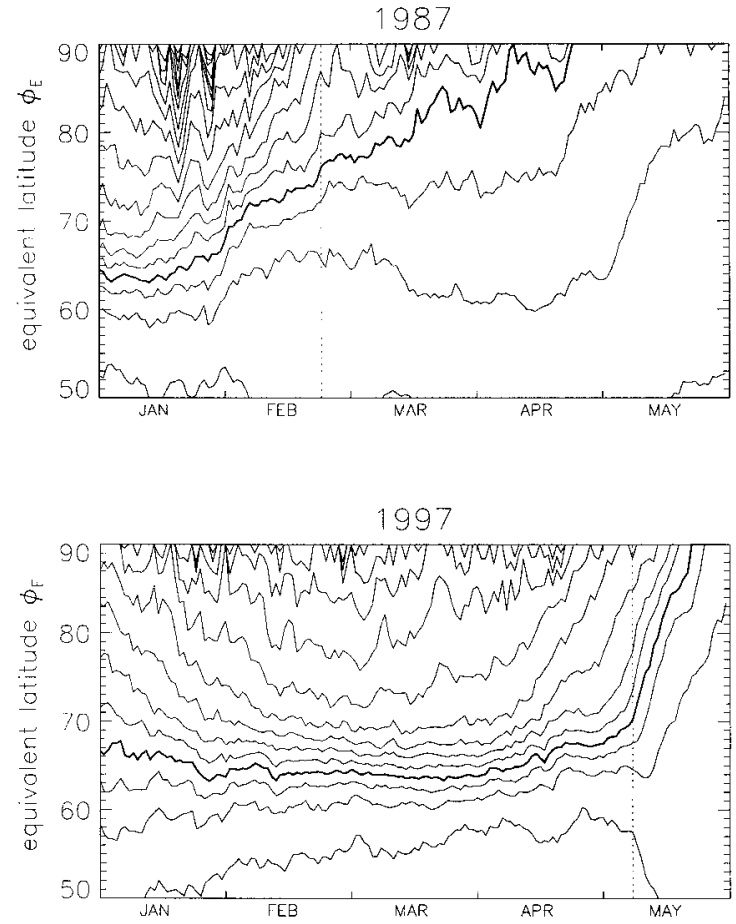

Fig. 4. Temporal evolution of the equivalent latitude $\varphi_{E}$ of PV contours on the $500 \mathrm{~K}$ isentropic surface for January to May of (a) 1987 and (b) 1997. Contour interval is $4 \mathrm{PVU}$ and the thick contour is $\mathrm{PV}=42$ PVU. Vertical dashed line is date of vortex breakup using Nash et al. (1996) criteria.

esting feature of some of the early breakups is that the decay occurs in steps, and there is a period after the breakup when vortex remnants remain the same size (and can even slightly increase in size), e.g., 1963 and 1973.

As a result of the above differences, the interannual variability in the time required for the area enclosed by PV contours to fall below a threshold value decreases as the threshold value decreases. For example, the date that the equivalent latitude $\varphi_{E}$ of the $\mathrm{PV}=42 \mathrm{PVU}$ (Figure 6) falls below $75^{\circ}$ varies between mid February to early May, whereas for $\varphi<85^{\circ}$ there is a much reduced range (late April to early May). This suggests that it takes a long time for the vortex to be completely mixed into midlatitudes in early breakup years but that the mixing will occur rapidly for late breakups, and that the complete mixing of vortex air is relatively insensitive to timing of breakup.

The above differences in the decay of the vortex are also observed in other diagnostics of the vortices. For example, we have performed a similar analysis using a diagnostic of the polar jet speed. We define the jet speed $u_{j e t}$ as the maximum wind speed averaged around any PV contour, i.e. for each PV contour we calculate the average wind speed around the contour and $u_{j e t}$ is the maximum value obtained. As shown in Figure 7 there is large difference in the evolution of $u_{j e t}$ between years with early and late breakups: In early breakup years the vortex strength is maximum in DecemberJanuary, and there is then a gradual decrease is strength over the following three months. In contrast, in late breakup years the maximum strength occurs in late February-March and there is a rapid decay in vortex strength in April.

The contrast between early and late breakups has also been noted in other studies. Pawson and Naujokat (1999) noted two classes of winter-summer transition in zonal winds, one involving a fairly rapid transition and the other an earlier transition to a weak westerly jet with a prolonged period of weak westerly winds. This is also consistent with the sensitivity of the vortex breakup date to the criteria parameters used for early breakups noted by Waugh et al. (1999). For many early breakup years a slight decrease in the critical area used to define the existence of the vortex results in a much later breakup date, whereas the defined date for late breakups are insensitive to the critical parameters used.

We have also examined the evolution of vortex area and jet strength at higher altitudes. At $800 \mathrm{~K}$ (which is near the top of the NCEP/ NCAR reanalyses) the above early-late breakup differences can also been seen, see Fig. 8. There is gradual decay for early breakups and a rapid decay for late breakups. There are however some quantitative differences. For example, at $800 \mathrm{~K}$ there is an increase in the area of the "edge" PV contour following the early breakups, the decay begins earlier at higher levels, and the decay in late breakups is more gradual than at $500 \mathrm{~K}$ (but the decay is still much more rapid than for early breakups). Also, there are several years (not shown) when there is a rapid 

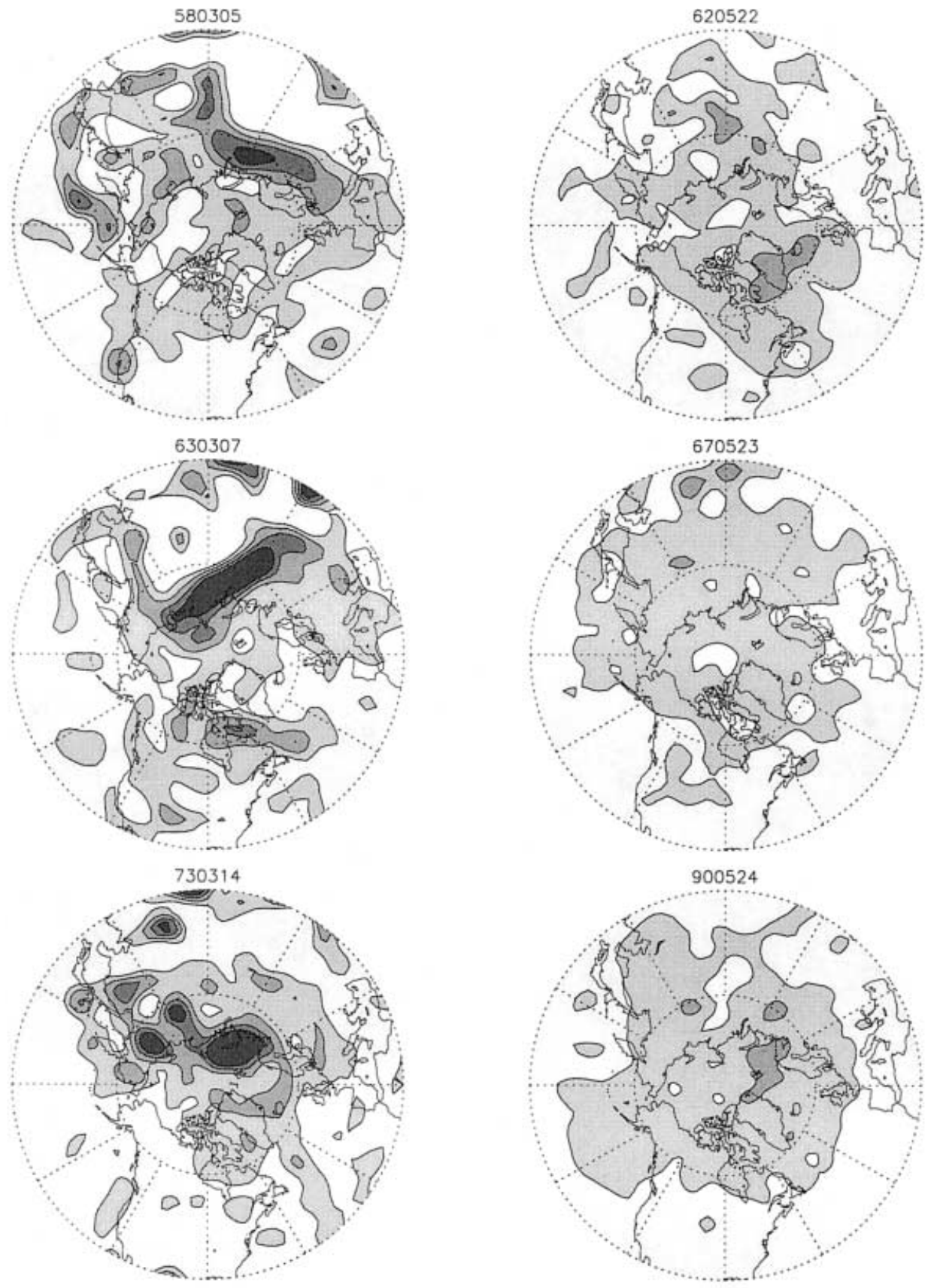

Fig. 5. As in Fig. 2 except for one month after the breakup in 1958, 1962, 1963, 1967, 1973, and 1990.

shrinking (destruction) of the vortex at $800 \mathrm{~K}$, following which a weak vortex is re-established and can persist for two or more months (e.g., 1967/68, 1969/70, and 1970/71, see PV maps and area diagnostics in Baldwin and Holton (1988)). These winters correspond to winters with mid-winter major warmings that have a major impact on the vortex in the middle and upper stratosphere but have only a minor impact in the lower stratosphere.

The above systematic differences between early and late breakup years (as defined at 
(a) Early Breakups

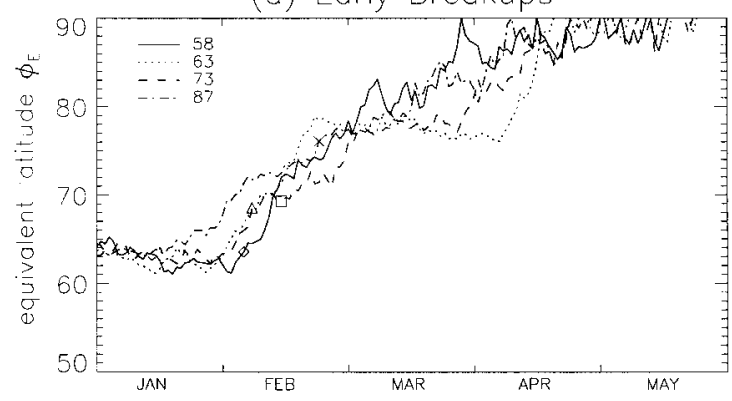

(b) Late Breakups

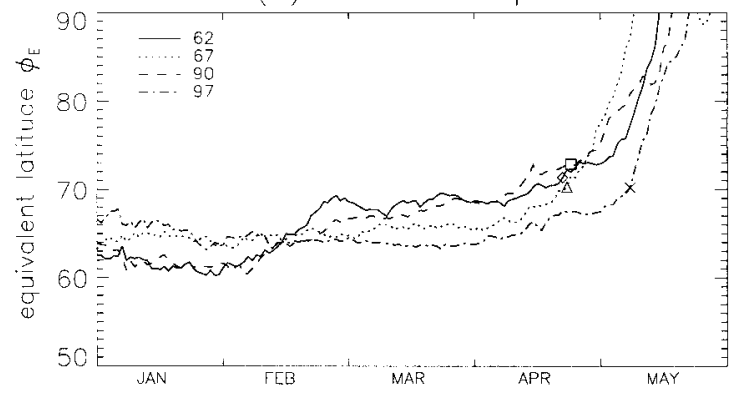

Fig. 6. Temporal evolution of $\varphi_{E}$ of $\mathrm{PV}=42 \mathrm{PVU}$ contour at $500 \mathrm{~K}$ for (a) early and (b) late breakups. Symbols correspond to breakup date, as shown in Fig. 1.

$500 \mathrm{~K})$ are not found at $1100 \mathrm{~K}$. The evolution at $1100 \mathrm{~K}$ during all years between 1979 and $2000^{2}$, is characterized by periods of rapid disruption and then re-establishment of the vortex, and in no years was there a smooth, gradual decay of the vortex. This more rapid disruption and re-establishment of the vortex is probably because of the shorter radiative timescale in the upper stratosphere (e.g., Newman and Rosenfield 1997).

It is interesting to ask why the decay of highPV coherent structures is so different for early and late vortex breakups. A possible reason for the differences is the seasonal variation in the solar radiative forcing (Hess 1990, 1991). During winter radiative cooling acts to maintain a westerly vortex, whereas in late spring/summer

2 As the top of the NCEP/NCAR re-analyses are at $10 \mathrm{hPa}$ NCEP Climate Prediction Center (CPC) analyses were used to examined the evolution in the upper stratosphere. However these are available only since 1979 .
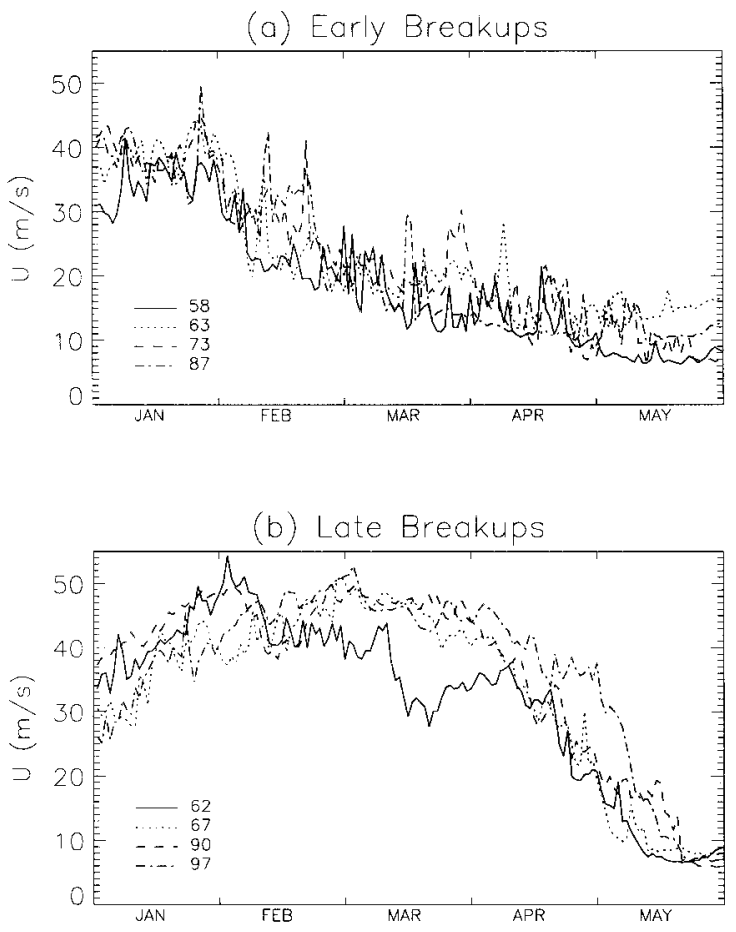

Fig. 7. As in Fig. 6 except for vortex jet strength $u_{\text {jet }}$ (see text for definition).

the radiative forcing drives the flow to zonal easterlies. So, when the vortex breaks up in mid-winter (early breakup) there is strong radiative cooling which acts to re-establish a polar vortex, whereas when the vortex breaks up in late spring (late breakup) there is no such radiative 'support' and there is a rapid demise of the vortex.

Although radiative effects may play a major role in late breakups this does not mean that the vortex evolution is solely radiatively driven. If radiation is the only process then we would expect the vortex evolution to be roughly symmetric, with late winter being similar to a time reversal of early winter (e.g., the simulation of a wave-free stratosphere shown in Fig. 6 of Butchart and Remsberg (1986)). However, this is not observed for winters with late breakups, as the decay is much more rapid than the formation. This suggests that wave forcing still plays a role even for winters when the vortex does not breakup until May. To examine this further we examine the amplitudes of wavenumber 1 and 2 in the geopotential height at 


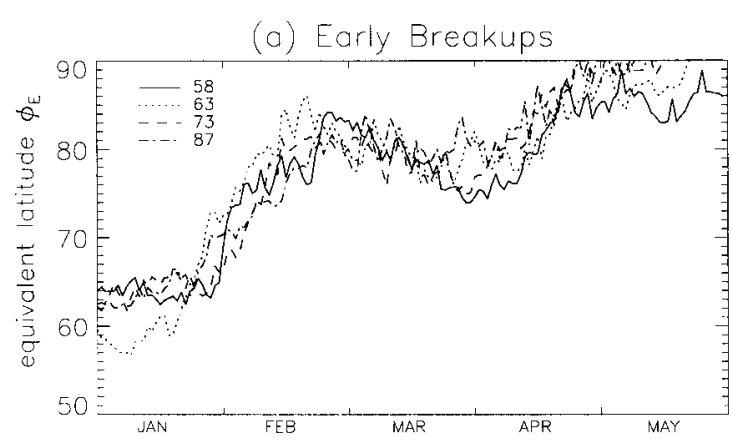

(b) Lote Breakups

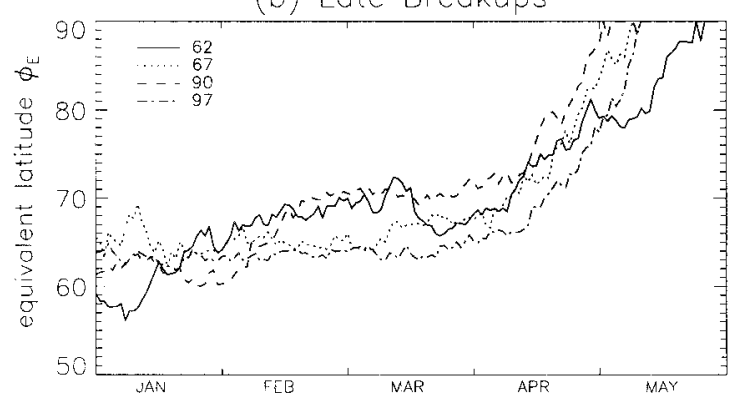

Fig. 8. As in Fig. 6 except for $P V=62$ PVU contour at $800 \mathrm{~K}$.
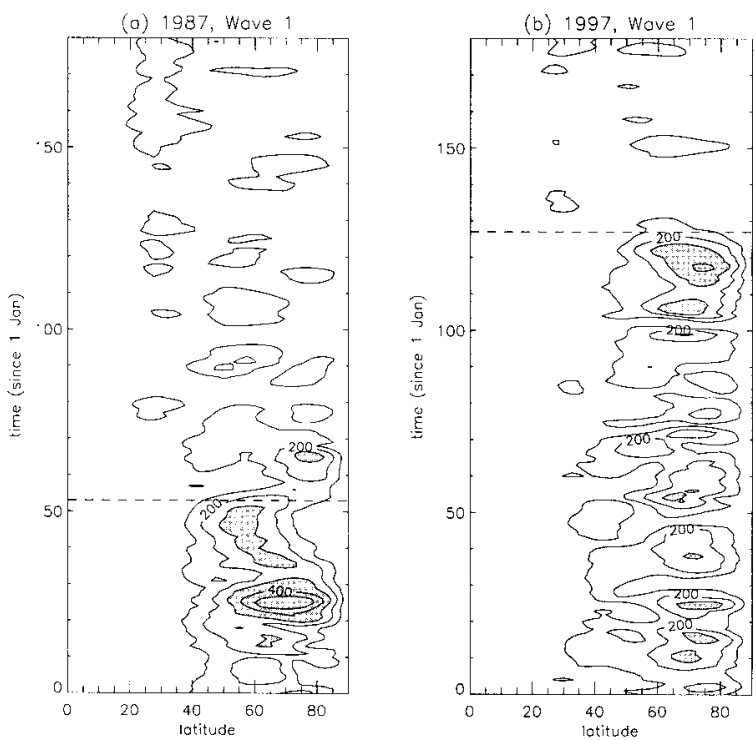

Fig. 9. Latitude-time plots of amplitude of wavenumber 1 in geopotential height at $100 \mathrm{hPa}$ in (a) 1987 and (b) 1997. Contour interval is $100 \mathrm{~m}$ with amplitude greater than $300 \mathrm{~m}$ shaded.

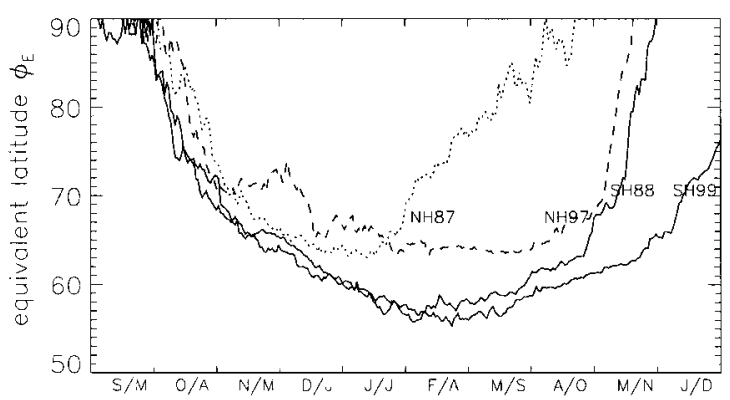

Fig. 10. Comparison of temporal evolution of $\varphi_{E}$, for PV contour $=42 \mathrm{PVU}$, for early and late Arctic (1987 and 1997) and Antarctic (1988 and 1999) vortex breakups.

$100 \mathrm{hPa}$. Figure 9 shows the time series of the $100 \mathrm{hPa}$ wavenumber 1 amplitude in 1987 and 1997 , and in both years a short ( $\approx 10$ day) period of large amplitudes occurs just before the breakup (dashed lines). Similar plots for other early and late breakups also show pulses in the amplitude of wavenumber 1 and/or 2 just before the breakup (not shown), and support the hypothesis that wave forcing plays a role in the break up of the vortex for both early and late breakups.

It is interesting to compare the evolution and breakup of the Arctic vortex to that of the Antarctic vortex. Figure 10 compares the evolution of the equivalent latitude of the $\mathrm{PV}= \pm 42$ PVU contour for the 1988 and 1999 Antarctic vortices (earliest and latest Antarctic vortex breakups since 1979) with those for the Arctic vortex in 1986/1987 and 1996/1997 (the time series in the two hemispheres are shifted by six months so the same seasons are being compared). As noted previously (e.g., Waugh \& Randel 1999; Waugh et al. 1999) the breakup of the Antarctic vortex occurs later than the Arctic vortex, and from Figure 10 we can see that even the latest Arctic vortex breakup (1997) occurs before the earliest Antarctic vortex breakup (1988). Also, there are no gradual breakups in the southern hemisphere: Every year the remnants of the Antarctic vortex disappear within a month.

\section{Contour advection calculations}

The above examination of the analyzed PV shows that there can be dramatic differences in 
the decay of coherent vortex structures following the breakup of the main polar vortex. But as the analyzed PV cannot resolve fine-scale features these data cannot be used to diagnose the ultimate mixing of vortex air with surrounding air. As outlined in Section 2, we use contour advection (CA) calculations to examine the stirring (stretching and folding) driven by the large-scale wind field, which produces a cascade from large to small scales (and leads to eventual mixing). As discussed in Section 2 the rate of lengthening of contours in the $\mathrm{CA}$ calculations is a measure of this stirring.

Although our primary interest is the stirring/ mixing of vortex air with surrounding air during and after the break up of the Arctic vortex, we examine the lengthening of contours for a range of equivalent latitude over the first six months of the calendar year (rather than just at the time of vortex breakup). This enables the full temporal evolution of the stirring to be examined, including comparisons of post-breakup values with those from mid-winter values when a strong vortex exists, and also enables the spatial variation of the stirring to be examined (e.g., inside and outside the vortex).

For each year examined, we have performed a series of 10-day CA calculations (one every five days covering the first six months) initialized with the PV contours which correspond to equivalent latitudes $\varphi_{E}=45^{\circ}, 50^{\circ}, \ldots 80^{\circ}$. For each contour the stretching rate $S$ is calculated from the increase in contour length over the duration of the calculation.

Figure 11 shows equivalent latitude versus time contour plots of stretching rate $S$ for (a) 1987 and (b) 1997. There are large spatial and temporal variations in $S$ (particularly at high latitudes) in both years, with both similarities and differences between the two years.

In both years there is a period when there is a minimum in $S$ in the vortex edge region $\left(S<1.0 \times 10^{-6} \mathrm{~s}^{-1}\right.$; which corresponds to an efolding time of over 10 days) and high values in the surrounding surf zone $\left(S \approx 2.5 \times 10^{-6} \mathrm{~s}^{-1}\right.$, e-folding time of around 4 days). These periods (January 1987, mid-January to mid-April 1997) correspond to the periods when there is a strong (isolated) polar vortex. (A minimum in $S$ at the vortex edge during mid-winter has been noted in several previous studies, e.g., Chen (1994), Waugh et al. (1994).) In both years, fol-
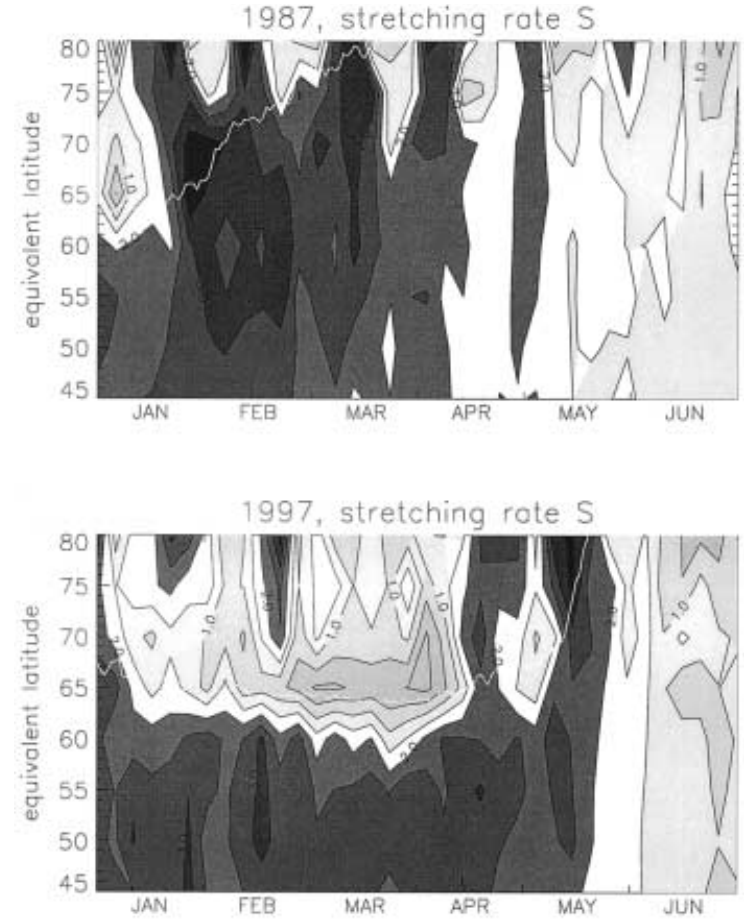

Fig. 11. Equivalent latitude versus time contour plot of stretching rate $S$ for (a) 1987 and (b) 1997. Contour interval is $0.5 \times 10^{-6} \mathrm{~s}^{-1}$, dark shading is $S>$ $2 \times 10^{-6} \mathrm{~s}^{-1}$, and light shading $S<$ $1 \times 10^{-6} \mathrm{~s}^{-1}$. White contour is $\varphi_{E}$ of PV contour $=42$ PVU (bold curves in Fig. $4)$.

lowing this period there is an increase in $S$ in the edge region $\left(\varphi_{E} \approx 65-70^{\circ}\right)$. This increase in stirring corresponds to the beginning of the break up of the vortex, and occurs around a month before the breakup date (the white contour corresponds to the equivalent latitude of the $\mathrm{PV}=42 \mathrm{PVU}$ contour). Finally, in both years there is a seasonal transition in $S$ in midlatitudes, from large values in mid-winter when there is a strong vortex $\left(\approx 2.5 \times 10^{-6} \mathrm{~s}^{-1}\right)$ to much smaller values in the summer $\left(\approx 1.0 \times 10^{-6} \mathrm{~s}^{-1}\right)$. During this post-breakup transition there is little latitudinal variation in the stirring.

Although there are the above similarities between the two years, there are some large differences. The transition in mid-latitudes from large winter values to small summer values differs between the two years. In 1987 the 

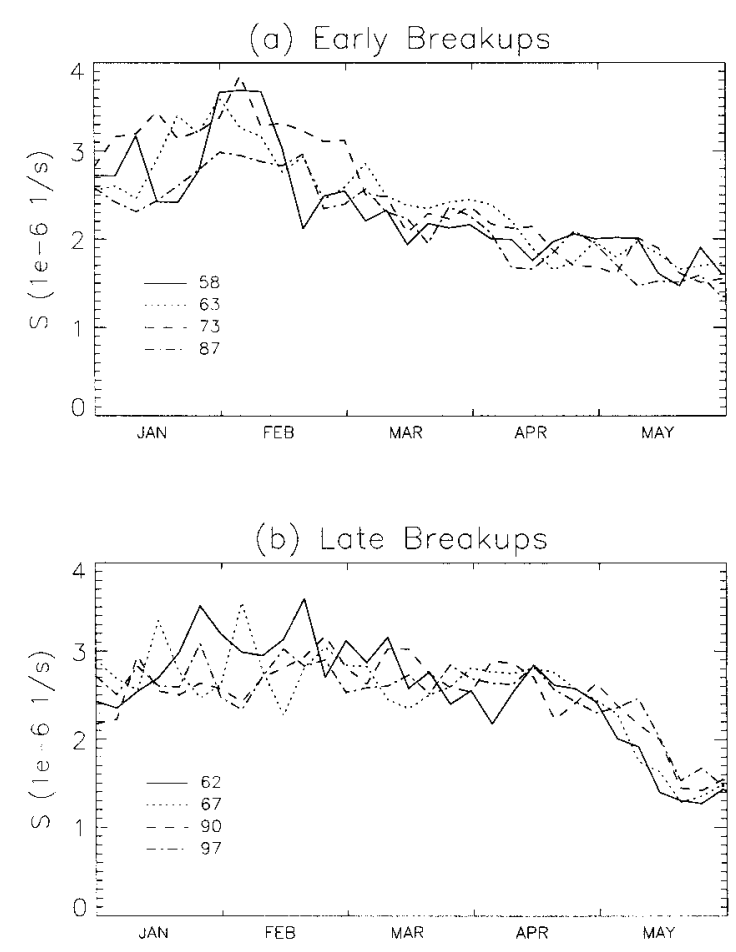

Fig. 12. As in Fig. 6 except for stretching rate $S$ from CA calculations. $S$ shown is the average from three PV contour with $\varphi_{E}=45,50,55^{\circ}$.

transition is more gradual and begins earlier than in 1997 (see Fig. 12 below). There are also differences at high latitudes around the time of the vortex breakup. The values in the vortex edge region $\left(\varphi_{E} \approx 65-75 \mathrm{~N}\right)$ are much larger during the early breakup in February 1987 than those during the late breakup in May $1997\left(S \approx 1.0 \times 10^{-6} \mathrm{~s}^{-1}\right.$ compared to $2.0 \times$ $\left.10^{-6} \mathrm{~s}^{-1}\right)$. This difference indicates that there is an early-late breakup difference in the mixing of vortex edge air into mid-latitudes during the vortex breakup.

These differences in the stirring between the early (1987) and late (1997) breakup also occur for the other early and late breakups. In years with an early breakup the stretching rate decreases gradually from February as the vortex decays, whereas in late breakups high stretching rates are sustained until April when they decrease dramatically as the vortex rapidly breaks up. For example, Fig. 12 shows the evolution of $S$, averaged over PV contours with $\varphi_{E}=45,50,55^{\circ}$, for the several early and late breakup years. Note the similar timing of the decrease in stretching rates and area enclosed by PV contours, see Fig. 6. Also note that $S$ during, and immediately after, the vortex breakup is higher in early breakup years.

The above correspondence between the vortex strength/decay and stretching rates in midlatitudes is not a coincidence as the wind field, which produces the stretching and folding of material contours, changes as the PV structure changes. As vortex remnants gradually decay during an early breakup there is a corresponding gradual decrease in the wind shear and stretching and folding. On the other hand when there is a long-lasting strong vortex there is sustained vigorous stirring as a result of the strong shear at the vortex edge, until the rapid demise of the vortex which causes a rapid drop in wind shear and the stretching rate.

Together with the above seasonal variation in contour-lengthening rates there is also a large difference in evolution and structures formed in CA calculations. During mid-winter (when there is a strong vortex), thin filamentary structures are formed which are wrapped around the vortex, with rapid lengthening of the material contours. In contrast, the slower stirring during summer produces fewer filamentary structures and, as there is no polar vortex, there is larger meridional spreading of the contour. This is illustrated in Fig. 13 which compares contours from 10-day CA calculations initialized as the PV contour with $\varphi_{E}=55^{\circ}$ on January 1, 1997 and June 1, 1997.

The relationship between $S$ and strain rates in an Eulerian frame of reference can be quantified by examining the strain-rotation parameter

$$
\begin{aligned}
Q= & \frac{1}{2} \mathbf{D}: \mathbf{D}-\frac{1}{4} \zeta^{2}, \\
= & \frac{1}{2 a^{2}}\left\{\left(\frac{1}{\cos \varphi} \frac{\partial u}{\partial \lambda}-v \tan \varphi\right)^{2}\right. \\
& \left.+\left(\frac{\partial v}{\partial \varphi}\right)^{2}+2 \frac{\partial u}{\partial \varphi}\left(\frac{1}{\cos \varphi} \frac{\partial u}{\partial \lambda}+u \tan \varphi\right)\right\},
\end{aligned}
$$

where $\mathbf{D}$ is the rate of deformation tensor and $\zeta$ the relative vorticity. This quantity measures the relative contribution of strain and rotation on fluid elements, and has been used previously to examine simulations of two-dimensional 

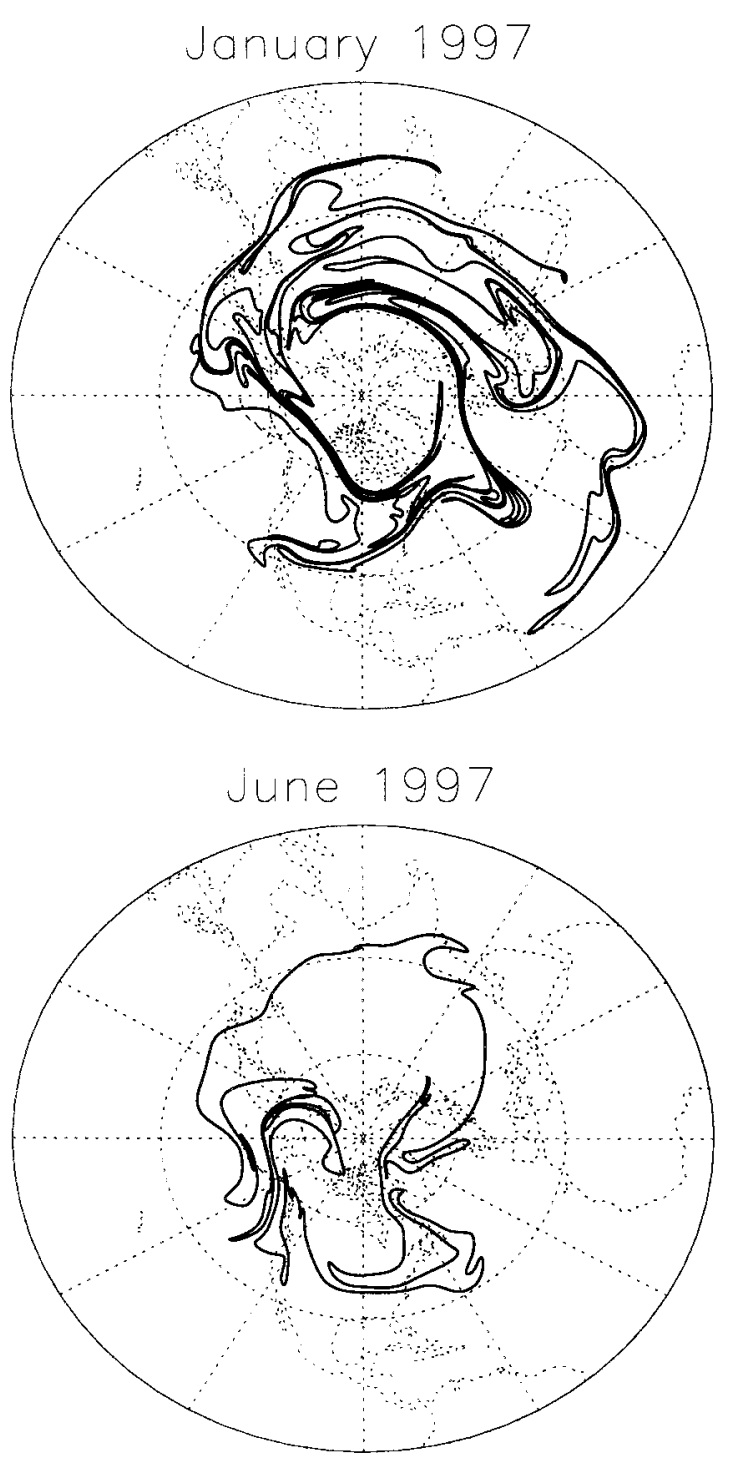

Fig. 13. Maps of contours after 10 day CA calculations initialized as the PV contour with $\varphi_{E}=55^{\circ}$ on (a) 1 January and (b) 1 June 1997.

turbulence (McWilliams 1984; Brachet et al. 1988), the flow in stratospheric models (Haynes 1990; Fairlie 1995), and in a parameterization of stratospheric mixing (Fairlie et al. 1999). Positive values of $Q$ indicate regions where strain predominates and fluid elements are stretched, whereas negative $Q$ indicate regions where rotation predominates. In regions dominated by strain $(Q>0)$ line elements are ex-
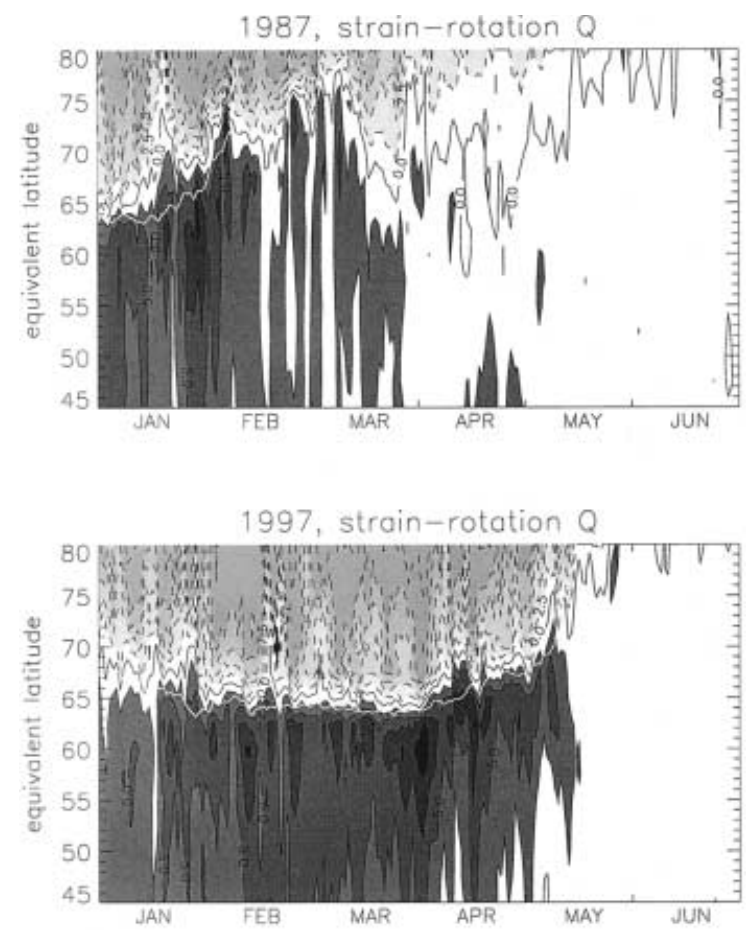

Fig. 14. As in Fig. 11 except for strainrotation parameter $\operatorname{sgn}(Q)|Q|^{1 / 2}$. Contour interval is $2.5 \times 10^{-6} \mathrm{~s}^{-1}$, dark shading is greater $2.5 \times 10^{-6} \mathrm{~s}^{-1}$, light shading less than $-2.5 \times 10^{-6} \mathrm{~s}^{-1}$, and dashed contours correspond to $Q<0$.

pected to ultimately increase in length as $\exp \left(Q^{1 / 2} t\right) \quad$ McWilliams 1984; Brachet et al. 1988), and hence $Q^{1 / 2}$ and $S$ should be of similar magnitude in these regions.

Figure 14 shows equivalent latitude versus time contour plots of $\operatorname{sgn}(Q)|Q|^{1 / 2}$ for (a) 1987 and (b) 1997. The seasonal variation in $Q$ is generally consistent with the variations in PV and the contour stretching rate $S$. When there is a strong vortex, there are large negative values inside the vortex (indicating predominance of rotation) and large positive values of $Q$ in mid-latitudes (indicating predominance of stretching of fluid elements in mid-latitudes). In contrast, after the vortex breakup there are much weaker (generally positive) values of $Q$ at all latitudes, indicating much weaker stretching of fluid elements throughout the hemisphere. The interannual variations in $Q$ between 1987 and 1997 are also similar to those 

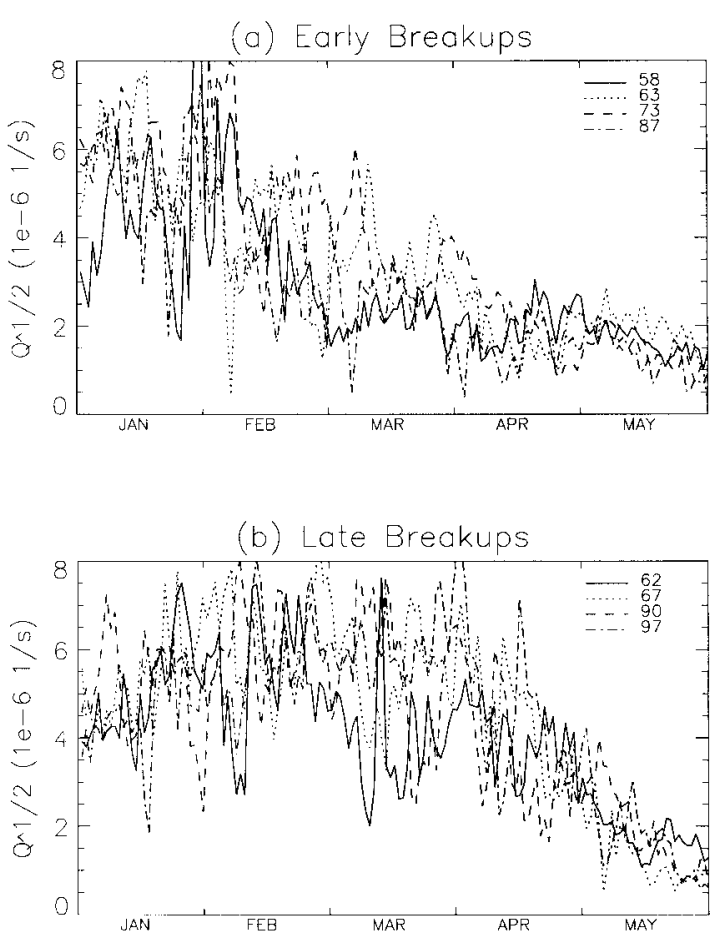

Fig. 15. As in Fig. 12 except for strainrotation parameter $Q^{1 / 2}$ averaged over $\varphi_{E}=45^{\circ}$ to $60^{\circ}$.

in PV and $S$. In particular, whereas there is a sharp decrease in $Q$ in 1997 there is a more gradual decrease in 1987.

The agreement in seasonal evolution and magnitude of $Q^{1 / 2}$ and $S$ also occurs in the other years examined. In particular, in early breakup years there is a more gradual transition to the small summer values than for the late breakup years. For example, Figure 15 shows the temporal evolution of $Q^{1 / 2}$ averaged over $\varphi_{E}=45^{\circ}$ to $60^{\circ}$ for several (a) early and (b) late breakup years. Not only are the temporal variations in $Q>0$ and $S$ similar but $Q^{1 / 2}$ is the same order of magnitude as $S$ (the maximum $Q^{1 / 2}$ is around twice that of $S$ ).

Finally, we contrast the above seasonal evolution in $S$ with that of another diagnostic of stirring/mixing. Using a modified Lagrangian mean formalism, Nakamura (1995) introduced the "equivalent length" diagnostic that is a measure of the geometric structure of tracer fields. Regions of large equivalent length are associated with regions of strong stirring whereas regions of small values with weak stirring and "mixing barriers". Haynes and Shuckburgh (2000) and Allen and Nakamura (2001) calculated the equivalent length (which can also be expressed as an "effective diffusivity") from isentropic transport calculations driven by analyzed winds, and these calculations show an increase in equivalent length in the lower stratosphere after the vortex breakup, with larger values in summer than in the mid-winter. (Similar calculations using the NCEP reanalyses for the years examined here show very similar results, with largest values in summer (Jun Ma, person. comm.).) Hence this diagnostic suggests that there the stirring/ mixing in summer is greater than in the midwinter surf zone surrounding the vortex. This is inconsistent with both our calculations of $S$ from CA calculations and the strain-rotation parameter $Q$. The reason for the differences between diagnostics is currently under investigation.

\section{Concluding remarks}

There is large interannual variability not only in the timing of the breakup of the Arctic lower stratospheric vortex but also in the characteristics of the mixing of vortex air into middle latitudes, with very different characteristics for early and late breakups. In early break up years (when the vortex breaks up in February and early March) the remnants of the vortex survive as coherent PV structures for around two months, whereas in late breakups (late April and May) the vortex PV remnants quickly disappear. There is a similar contrast between early and late breakups in the stirring (as diagnosed by contour advection calculations) in the region around the vortex, with a gradual decrease in the stretching rates occurring when the vortex breaks up early and an abrupt transition occurring in late breakup years.

The above suggests that there are large differences in the mixing of vortex air into the surrounding middle latitudes between years with early and late breakups. In early breakup years the existence of long lasting coherent vortex structures limits the mixing of inner vortex air with mid-latitude air, but the strong stirring surrounding the vortex remnants leads to rapid mixing of the air outside the coherent remnants with surrounding air. In late breakup years vortex air is relatively isolated until 
the breakup occurs in April or May. After the breakup coherent PV structures decay rapidly, and vortex air is no longer trapped in coherent cyclonic structures. However at the same time there is a rapid decrease in stirring rates which may result in slow mixing of the vortex air into middle latitudes. (Note that although coherent PV remnants are short lived this could be because of radiative warming which does not affect chemical tracers, and remnants of chemical tracers may have a longer lifetime.) The above variations in the mixing during the vortex breakup are consistent with the results of Hess (1991) discussed in the Introduction. The slow mixing following a late breakup is also consistent with the observations of vortex fragments in late June 1997 (e.g., Hermann et al. 1998; Strunk et al. 2000), and the recent modeling study of Orsolini (2001).

There are several issues that need to be examined in future work. One is the dynamics behind early and late breakups, and in particular the cause of gradual versus rapid decay of PV remnants (and relative roles of dynamical and radiative processes). Another issue is the three-dimensional structure of the remnants, and filaments. Hess (1991) showed that the tilting of features in the vertical and accompanying decrease in vertical lengths scales plays an important role in mixing of vortex air (see also Haynes and Anglade (1997)). Also, we have considered only PV or idealized conserved tracers, and not real chemical constituents. To address both the above issues we need to examine (high-resolution) three-dimensional fields of long-lived chemical constituents. At present such observational data are very limited, and it will be necessary to use highresolution three-dimensional model calculations (e.g., Orsolini 2001; Piani et al. 2002) to examine these issues. Note that the early breakups in 1999 and 2001 (combined with the late breakups in early and mid-1990s) means that meteorological analyses from the last decade can be used to drive chemical transport models and examine both early and late breakups.

\section{Acknowledgments}

We thank Paul Newman for providing the NCEP/NCAR analyses, and Eric Nash for providing vortex breakup dates shown in Fig. 1.
We also thank two anonymous reviewers for helpful comments. This work was supported by the NASA Atmospheric Chemistry and Modeling Project.

\section{References}

Allen, D.R. and N. Nakamura, 2001: A Seasonal Climatology of Effective Diffusivity in the Stratosphere, J. Geophys. Res., 106, 7917-7935.

Baldwin, M.P. and J.R. Holton, 1988: Climatology of the stratospheric polar vortex and planetary wave breaking. J. Atmos. Sci., 45, 1123-1142.

Balluch, M.G. and P.H. Haynes, 1997: Quantification of lower stratospheric mixing processes using aircraft data, J. Geophys. Res., 102, 2348723504.

Brachet, M.E., M. Meneguzzi, H. Politano, P.L. Sulem, 1988: The dynamics of freely decaying two-dimensional turbulence. J. Fluid Mech., 194, 333-349.

Butchart, N. and E.E. Remsberg, 1986: The area of the stratospheric polar vortex as a diagnostic for tracer transport on an isentropic surface, $J$. Atmos. Sci., 43, 1319-1339.

Chen, P., 1994: The permeability of the Antarctic vortex edge, J. Geophys. Res., 99, 2056320571.

Coy, L., E.R. Nash, and P.A. Newman, 1997: Meteorology of the polar vortex: Spring 1997, Geophys. Res. Lett., 24, 2693-2696.

Fairlie, T.D.A., 1995: Three-dimensional transport simulations of the dispersal of volcanic aerosol from Mount Pinatubo, Quart. J. Roy. Meteor. Soc., 121, 1943-1980.

Fairlie, T.D., R.B. Pierce, J.A. Al-Saadi, W.L. Grose, J.M. Russell, M.H. Proffitt, and C.R. Webster, 1999: The contribution of mixing in Lagrangian photochemical predictions of polar ozone loss over the Arctic in summer 1997, J. Geophys. Res., 104, 26597-26609.

Haynes, P.H., 1990: High-resolution three-dimensional modelling of stratospheric flows: quasi2D turbulence dominated by a single vortex. In Topological Fluid Mechanics (ed., Moffatt, H.K., and Tsinober, A.), Cambridge University Press., 345-354.

and J. Anglade, 1997: The vertical-scale cascade in atmospheric tracers due to large-scale differential advection. J. Atmos. Sci., 54, 11211135.

Haynes, P. and E. Shuckburgh, 2000: Effective diffusivity as a diagnostic of atmospheric transport. Part I: stratosphere, J. Geophys. Res., 105, 22777-22794.

Herman, R.L., D.C. Scott, C.R. Webster, R.D. May, E.J. Moyer, R.J. Salawitch, Y.L. Yung, G.C. 
Toon, B. Sen, J.J. Margitan, K.H. Rosenlof, H.A. Michelsen, and J.W. Elkins, 1998: Tropical entrainment time scales inferred from stratospheric N2O and CH4 observations, Geophys. Res. Lett., 25, 2781-2784.

Hess, P.G., 1990: Variance in trace constituents following the final stratospheric warming, $J$. Geophys. Res., 95, 13765-13780.

_, 1991: Mixing processes following the final stratospheric warming, J. Atmos. Sci., 48, 1625-1641.

Kalnay, E., M. Kanamitsu, R. Kistler, W. Collins, D. Deaven, L. Gandin, M. Iredell, S. Saha, G. White, J. Woollen, Y. Zhu, M. Chelliah, W. Ebisuzaki, W. Higgins, J. Janowiak, K.C. Mo, C. Ropelewski, J. Wang, A. Leetmaa, R. Reynolds, R. Jenne, and D. Joseph, 1996: The NCEP/NCAR 40-year reanalysis project, Bull. Amer. Meteor. Soc., 77, 437-471.

Knudsen, B.M. and J.U. Grooss, 2000: Northern midlatitude stratospheric ozone dilution in spring modeled with simulated mixing, J. Geophys. Res., 105, 6885-6890.

Knudsen, B.M., W.A. Lahoz, A. O’Neill, and J.J. Morcrette, 1998: Evidence for a substantial role for dilution in northern mid-latitude ozone depletion. Geophys. Res. Lett., 25, 4501-4504.

Manney, G.L., R.W. Zurek, M.E. Gelman, A.J. Miller, and R. Nagatani, 1994: The anomalous Arctic lower stratospheric polar vortex of 1992-1993. Geophys. Res. Lett., 21, 2405-2408.

McWilliams, J.C., 1984: The emergence of isolated coherent vortices in turbulent flow. J. Fluid Mech., 146, 21-43.

Nakamura, N., 1995: Modified Langragian-mean diagnostics of the stratospheric polar vortices 1 . Formulation and analysis of GFDL SKYHI GCM, J. Atmos. Sci., 52, 2096-2108.

Nash, E.R., P.A. Newman, J.E. Rosenfield, and M.R. Schoeberl, 1996: An objective determination of the polar vortex using Ertel's potential vorticity, J. Geophys. Res., 101, 9471-9478.

Newman, P.A., L.R. Lait, M.R. Schoeberl, M. Seablom, L. Coy, R. Rood, R. Swinbank, M. Proffitt, M. Loewenstein, J.R. Podolske, J.W. Elkins, C.R. Webster, R.D. May, D.W. Fahey, G.S. Dutton, and K.R. Chan, 1996: Measurements of polar vortex air in the midlatitudes, J. Geophys. Res., 101, 12879-12893.

- and J. Rosenfield, 1997: Stratospheric thermal damping rates, Geophys. Res. Lett., 24, 433-436.

Ngan, K. and T.G. Shepherd, 1999: A closer look at chaotic advection in the stratosphere. Part II: Statistical diagnostics J. Atmos. Sci., 56, 41534166.
Norton, W. A., 1994: Breaking Rossby waves in a model stratosphere diagnosed by a vortexfollowing coordinate system and a contour advection technique, J. Atmos. Sci., 51, 654673.

Orsolini, Y.J., 2001: Long-lived tracer pattersn in the summer polar statosphere. Geophys. Res. Lett., 28, 3855-3858.

Pawson, S. and B. Naujokat, 1999: The cold winters of the middle 1990s in the northern lower stratosphere, J. Geophys. Res., 104, 1420914222.

Piani, C., W.A. Norton, A.M. Iwi, E.A. Ray, and J.W. Elkins, 2002: Transport of ozone depleted air on breakup of the stratospheric polar vortex in spring/summer 2000. J. Geophys. Res., to appear.

Pierce, B.R. and T.D.A. Fairlie, 1993: Chaotic advection in the stratosphere: Implications for the dispersal of chemically perturbed air from the polar vortex, J. Geophys. Res., 98, 1858918595.

Plumb, R.A., D.W. Waugh, R.J. Atkinson, M.R. Schoeberl, L.R. Lait, P.A. Newman, E.V. Browell, A. Simmons, M. Loewenstein, and D.W. Toohey, 1994: Intrusions into the lower stratospheric Arctic vortex during the winter of 1991/ 92, J. Geophys. Res., 99, 1089-1106.

, D.W. Waugh, and M. Chipperfield, 2000: The effects of mixing on tracer relationships in the polar vortices, J. Geophys. Res., 105, 1004710062.

Randel, W.J. and F. Wu, 1999: Cooling of the Arctic and Antarctic polar stratosphere due to ozone depletion, J. Climate, 12, 1467-1479.

Shindell, D., D. Rind, and P. Lonergan, 1998: Increased polar stratospheric ozone losses and delayed eventual recovery owing to increasing greenhouse-gas concentrations. Nature, 392, 589-592.

Strunk, M., A. Engel, U. Schmidt, C.M. Volk, T. Wetter, I. Levin, H. Glatzel-Mattheier, 2000: $\mathrm{CO}_{2}$ and $\mathrm{SF}_{6}$ as stratospheric age tracers: consistency and the effect of mesospheric $\mathrm{SF}_{6}$ loss, Geophys. Res. Lett., 25, 341-344.

Waugh, D.W. and R.A. Plumb, 1994: Contour advection with surgery: A technique for investigating fine scale structure in tracer transport, $J$. Atmos. Sci., 51, 530-540.

, R.A. Plumb, R.J. Atkinson, M.R. Schoeberl, L.R. Lait, P.A. Newman, M. Loewenstein, D.W. Toohey, L.M. Avallone, C.R. Webster and R.D. May, 1994: Transport of material out of the stratospheric Arctic vortex by Rossby wave breaking, J. Geophys. Res., 99, 10711088. 
R.A. Plumb, J.W. Elkins, D.W. Fahey, K.A. Boering, G.S. Dutton, C.M. Volk, E. Keim, R.S. Gao, B.C. Daube, S.C. Wofsy, M. Loewenstein, J.R. Podolske, K.R. Chan, M.H. Proffitt, K.K. Kelly, P.A. Newman, and L.R. Lait, 1997: Mixing of polar vortex air into middle latitudes as revealed by tracer-tracer scatter plots. $J$. Geophys. Res., 102, 13119-13134.

and W.J. Randel, 1999: Climatology of Arctic and Antarctic polar vortices using elliptical diagnostics, J. Atmos. Sci., 56, 1594-1613.

- — , S. Pawson, P.A. Newman, and E.R.
Nash, 1999: Persistence of the Lower Stratospheric Polar Vortices. J. Geophys. Res., 104, 27191-27201.

Zurek, R.W., G.L. Manney, A.J. Miller, M.E. Gelman, and R.M. Nagatani, 1996: Interannual variability of the north polar vortex in the lower stratosphere during the UARS mission, Geophys. Res. Lett., 23, 289-292.

Zhou, S.T., M.E. Gelman, A.J. Miller, and J.P. McCormack, 2000: An inter-hemisphere comparison of the persistent stratospheric polar vortex, Geophys. Res. Lett., 27, 1123-1126. 